\title{
A MACROSCOPIC STUDY ON THE MUSCLES AND TENDONS OF FOREPAWS IN THE ANATOLIAN BOBCAT (Lynx lynx)
}

\author{
Hasan Hüseyin Ari ${ }^{1,4^{*}}$, İbrahim Yurdakul², Gürsoy Aksoy ${ }^{3}$ \\ ${ }^{1}$ Department of Anatomy, ${ }^{2}$ Department of Surgical, Faculty of Veterinary Medicine, Cumhuriyet University, Sivas, ${ }^{3}$ Department of Anatomy, \\ Faculty of Veterinary Medicine, Kafkas University, Kars, ${ }^{4}$ Kyrgyz -Turkish Manas University Faculty of Veterinary Medicine, Department of \\ Anatomy, Bishkek, Turkey
}

*Corresponding author, E-mail: ibrahimyurdakul5858@hotmail.com, hasanh.ari@manas.edu.kg

\begin{abstract}
This study was performed on the tendons and muscles of two Anatolian bobcats (Lynx lynx). The research materials were donated by Republic of Turkey Ministry of the Forestry and Water Affairs Sivas Branch Manager. To achieve this objective, dissection and radiography were applied to two dead specimens. Digit I is radiographically rudimentary in the forepaw. The muscles and tendons of the forepaw in the bobcat are located in the cranial and caudal aspect of the antebrachium, the central manus and hypothenar region. The extensor muscles are situated on the cranial aspect of the antebrachium, while the flexor muscles are located on the caudal aspect of the antebrachium. The m. extensor carpi radialis in the extensor group has long and short portions; the $\mathrm{m}$. extensor digitorum lateralis et communis give rise to tendons associated with fingers; the fascia covering the muscles emerges on the lateral and medial border of the $\mathrm{m}$. extensor digitorum lateralis. The $\mathrm{m}$. flexor digitorum superficialis et profundus lie on the caudal aspect of the antebrachium; the superficial digital flexor tendons give rise to the origin of the bellies of the $\mathrm{m}$. flexor digitorum brevis; the $\mathrm{m}$. flexor digitorum profundus form a stout tendon from which the $\mathrm{mm}$. lumbricales originate on the palmar aspect of carpal joints; the tendon of the muscle perforates the tendon of the $\mathrm{m}$. flexor digitorum superficialis. The $\mathrm{mm}$. flexores digitorum profundi breves in the central manus group consist of the lateral and medial portions and insert on the palmar aspect of each proximal phalanx associated with the fingers. Other muscles in the group, adductores digitorum, end to those in the fingers.
\end{abstract}

Key words: Anatolian bobcat(Lynxlynx); forepaw; muscles; tendons; anatomy

\section{Introduction}

The bobcat (Lynx lynx), which is an endangered species and a medium-sized cat with a short tail, is a predatory carnivorous animal $(1,2)$. While the carnivore hind limb primarily serves as a locomotor organ, the forelimb may also be involved in both capturing and subduing prey (3, $4,5)$. In felids, forelimbs are particularly used to hold onto and position the struggling prey, though small prey specialists make less use of forelimbs in subduing prey. Therefore, the myology of the

Received:24November 2018

Accepted for publication: 4 September 2019 forelimbs of cats reflects ecomorphological history as well as adaptations to behavior (6).

In terms of insertion, the muscles related to the forepaw in the cranial compartment of the antebrachium are $\mathrm{m}$. extensor carpi radialis longus et brevis, m. extensor carpi ulnaris, $\mathrm{m}$. extensor communis, $\mathrm{m}$. extensor digitorum lateralis, $\mathrm{m}$. extensor pollicis longus, and $\mathrm{m}$. abductor pollicis longus $(7,8)$. While the functions of $\mathrm{m}$. extensor carpi radialis longus et brevis, and $\mathrm{m}$. extensor carpi ulnaris are involved in the carpal joints, the others affect the digital joints. Forepaw muscles and tendons in the manus can be divided into hypothenar, superficial, and central compartments of the manus (8). 
M. extensor carpi radialis longus originates from the lateral supracondylar ridge of the humerus in the felid $(8,9,10)$. After the muscle gives rise to a flat tendon in the distal third of the antebrachium, it passes through the common extensor retinaculum (8) and inserts onto the proximal shaft of the second metacarpal $(8,9,10)$.

Like the $\mathrm{m}$. extensor carpi radialis longus, the $\mathrm{m}$. extensor carpi radialis brevis springs from the lateral supracondylar ridge of the humerus in the felis family. The muscle becomes a tendon in the distal quarter of the antebrachium that passes through the common extensor retinaculum before inserting into the third metacarpal bone $(8,9,10$, $11,12)$.

The $\mathrm{m}$. extensor carpi ulnaris originates from the epicondyle of the humerus in carnivores $(8$, $9,10,11,12)$. The tendon of the muscle passes laterally over the carpus to end on the fifth metacarpal bone $(8,9,10,11,12)$. In addition, the tendon inserts in both the pisiform bone and its ligament in ocelots (8), while another branch of the tendon radiates into the flexor retinaculum in the cat (11).

It was established that the origin of $\mathrm{m}$. extensor digitorum lateralis was the lateral supracondylar bridge of the humerus in the ocelot (8) and cats (10). The muscle that has three bellies $(8,9,10$, $11,12)$ at the level carpal joint becomes a different number (three or four) of tendons in the carnivores. The tendons pass over the carpal joint and then fuse with the $\mathrm{m}$. extensor digitorium communis III-V digits in the carnivores $(8,9,10,11,12)$.

The $\mathrm{m}$. extensor digitorum communis with a different number of bellies arises from different areas of the humerus, for example, the lateral supracondylar bridge and epicondyle, in the carnivores $(8,9,10,11)$. After the muscle bellies become tendons serving digits II-V at the distal third of the radius (9), the tendons pass through the shared retinaculum on the carpus joint in the carnivores $(8,9,10,11)$.

The $\mathrm{m}$. extensor digiti I (pollicis) longus is only found in carnivores (10) and originates from the distal third of the ulna, covering the tendon of the $\mathrm{m}$. extensor digitorum lateralis, deep into the extensor tendons in the cats $(8,9,10,11,12)$. In the cat family, its tendon gives rise to two slender branches ending at the first and second digits $(8$, $9,10,11,12)$. A third branch that inserts into the third digit may exist in the cat family $(8,9)$.

The $\mathrm{m}$. abductor digiti I (pollicis) longus that acts as the abductor for the first digit in the carnivores (10) arises from the lateral aspects of the ulna and radius and travels distally and medially to pass superficially into the tendon of the $\mathrm{m}$. extensor carpi radialis in the carnivores. The muscle ends at the base of metacarpal I in the cat family $(8,9,10,11,12)$.

The muscles of the cranial compartment of the antebrachium that act as forepaw joints comprise the $\mathrm{m}$. flexor carpi radialis et ulnaris, $\mathrm{m}$. flexor digitorum superficialis et profundus, and $\mathrm{m}$. palmaris longus $(8,9,10,11,12)$.

The $\mathrm{m}$. flexor carpi radialis arises from the medial epicondyle of the humerus in carnivores $(8,9,10,11)$. Its tendon passes over the flexor side of the carpus to end at the palmar aspect of the third and second metacarpal bone in carnivores $(8,9,10,11)$.

The $\mathrm{m}$. flexor carpi ulnaris consists of the ulnar and humeral heads. The caput ulnare arises from the olecranon process of the ulna, while the caput humerale originates from the medial epicondyle of the humerus $(8,9,10,11,12)$. In the right limb of the ocelot, Julik et al. (8) stated that the caput ulnare consists of the distal and proximal bellies. In carnivores $(9,10,11)$, both heads end with a common tendon that is inserted into the accessory carpal bone, while in ocelots (8), both portions pass through a shared flexor retinaculum on the palmar aspect of the carpus to end at the pisiform carpal bone.

The $\mathrm{m}$. flexor digitorum superficialis stems from the medial epicondyle of the humerus in carnivores $(9,10,11,12)$, while the muscle that has three bellies serving digits II-IV emerges from the superficial aspect of the $\mathrm{m}$. flexor digitorum profundus in ocelots (8). In the cat family, the tendon of the muscle that becomes tendinous at the level of the carpus splits into five portions serving digits $\mathrm{I}-\mathrm{V}$ in the proximal third of the metacarpal bone $(9,10,11)$. In the cat family, all of the tendons pass deep into the proximal annular ligament of the digit they serve and divide to allow for the passage called the manica flexoria of the $\mathrm{m}$. flexor digitorum profundus $(8,9,10,11,12)$. Each of the tendons end at the proximal border of the middle phalanx of the first to fifth digits in the cats $(9,10,11)$.

The $\mathrm{m}$. flexor digitorum profundus is composed of three separable heads in carnivores $(9,10,11$, 12) or five heads in the ocelot (Julik et al., 2012). In carnivores $(9,10,11)$, the muscle heads are 
called caput humerale, radiale, and ulnare, while in the ocelot (8), the heads are named caput humerale laterale, mediale and profundus, caput ulnare, and capita radiale. The caput humerale that originates from the medial epicondyle of the humerus is composed of three distinguishable bellies and the strongest head in the cat $(9,10$, 11). The caput ulnare originates from the caudal border of the ulna and olecranon in the cats $(9,10,11,12)$. All the heads of the muscle are joined together to form the strongest tendon just proximal to the carpus in the cat family $(8,9$, $10,12)$. The conjoined tendon courses through a shared flexor retinaculum and continues distally to serve all five digits. In the proximal metacarpal region, when it detaches a thin tendon to the first digit, the main tendon divides into four powerful limbs for digits II-V in the cat family. They are enveloped by the tube-like cuff of the $\mathrm{m}$. flexor digitorum superficialis, called the manica flexoria, under the metacarpal pad in the cats. After the tendons initially pass through the proximal annular ligament and then the distal annular ligament at the proximal phalanx level of the digits served, they insert into the palmar aspects of the distal phalanx digits $(8,9,10,11,13)$.

The $\mathrm{m}$. palmaris brevis located in the superficial compartment of the manus originates from the lateral side of the flexor retinaculum. It then run transversely to insert on the metacarpal paw pad in the ocelot (8).

The $\mathrm{m}$. flexor digitorum brevis that is shaped like a cone in cats (11) is composed of two superficial bellies and one deep belly in the ocelot (8). The superficial belly springs from the deep and caudal aspect of the flexor retinaculum, while the deep belly originates from the deep lateral aspect of the tendon of the $\mathrm{m}$. palmaris longus in the distal quarter of the antebrachium. Two superficial bellies fuse and give rise to a shared tendon to digit $\mathrm{V}$, while the deep belly gives rise to a tendon to digit IV (8).

The $\mathrm{m}$. abductor digiti $\mathrm{V}$ belonging to the hypothenar compartment of the manus originates from the pisiform in the ocelot (8), while the muscle arises from the accessory carpal bone in cats (11). In both cats and ocelots, the muscle inserts into the base of the phalanx proximalis of digit $\mathrm{V}(8,11)$.

The muscles of the central compartment of the manus are $\mathrm{mm}$. lumbricales, $\mathrm{mm}$. adductors digitorum, and $\mathrm{mm}$. flexores profundi breves. $\mathrm{Mm}$. lumbricales are composed of four distinct bellies serving digits II-V. The bellies originate from the common tendon of the $\mathrm{m}$. flexor digitorum profundus and end at the base of the phalanx proximalis of their respective digits $(8,11)$.

The $\mathrm{mm}$. adductores digitorum serving digits I, II, and $\mathrm{V}$ arises from the transverse carpal ligament, and each muscle inserts onto the base of the phalanx proximalis of its respective digits in the cat family $(8,11)$.

The $\mathrm{mm}$. flexores profundi breves, except digit I, consist of a medial and lateral belly serving each digit; on the first digit, only a medial belly is present. The bellies of the muscle stem from the transverse carpal ligaments (8).

Because anatomical descriptions concerning the muscles and tendons of the paw in the Anatolian bobcat have not been found, in the present study, we aimed to describe a detailed macroanatomy of the muscles and tendons of the paw in the Anatolian bobcat.

\section{Materials and methods}

The study was conducted on two female Anatolian bobcats (cadaver I was $6.9 \mathrm{~kg}$ and cadaver II was $7.6 \mathrm{~kg}$ in weight, respectively). The animals were obtained from Republic of Turkey Ministry of the Forestry and Water Affairs Sivas Branch Manager. After the animals died of natural causes (14), they were immediately transported to Department of Anatomy of Faculty of Veterinary Medicine at Cumhuriyet University. The animals were fixed with $10 \%$ formalin via the carotid common artery to prepare the cadavers. Then, the forelimbs of the cadavers were dissected and photographed with a Canon 50D camera. Radiographic images of manus were taken in dorso-palmar position using PCMAX-100H ${ }^{\circledR}$ (led: input voltage: $3.3 \mathrm{VDC}, 2 \mathrm{~A}$ : Korea). The terminology used in the manuscript is in accordance with the prevailing Nomina Anatomica Veterinaria (15).

\section{Results}

The forepaw of first cadaver was $132.84 \mathrm{~mm}$ long and $42.33 \mathrm{~mm}$ wide, while measurement of other cadavers was $130.20 \times 41.55$. Each paw consisted of the first, second, third, fourth, and fifth fingers (Fig. 2F). The first finger, called the dewclaw, was rudimental and composed of the first metacarpal, the proximal and distal phalanx bones (Fig. 2F/I). 

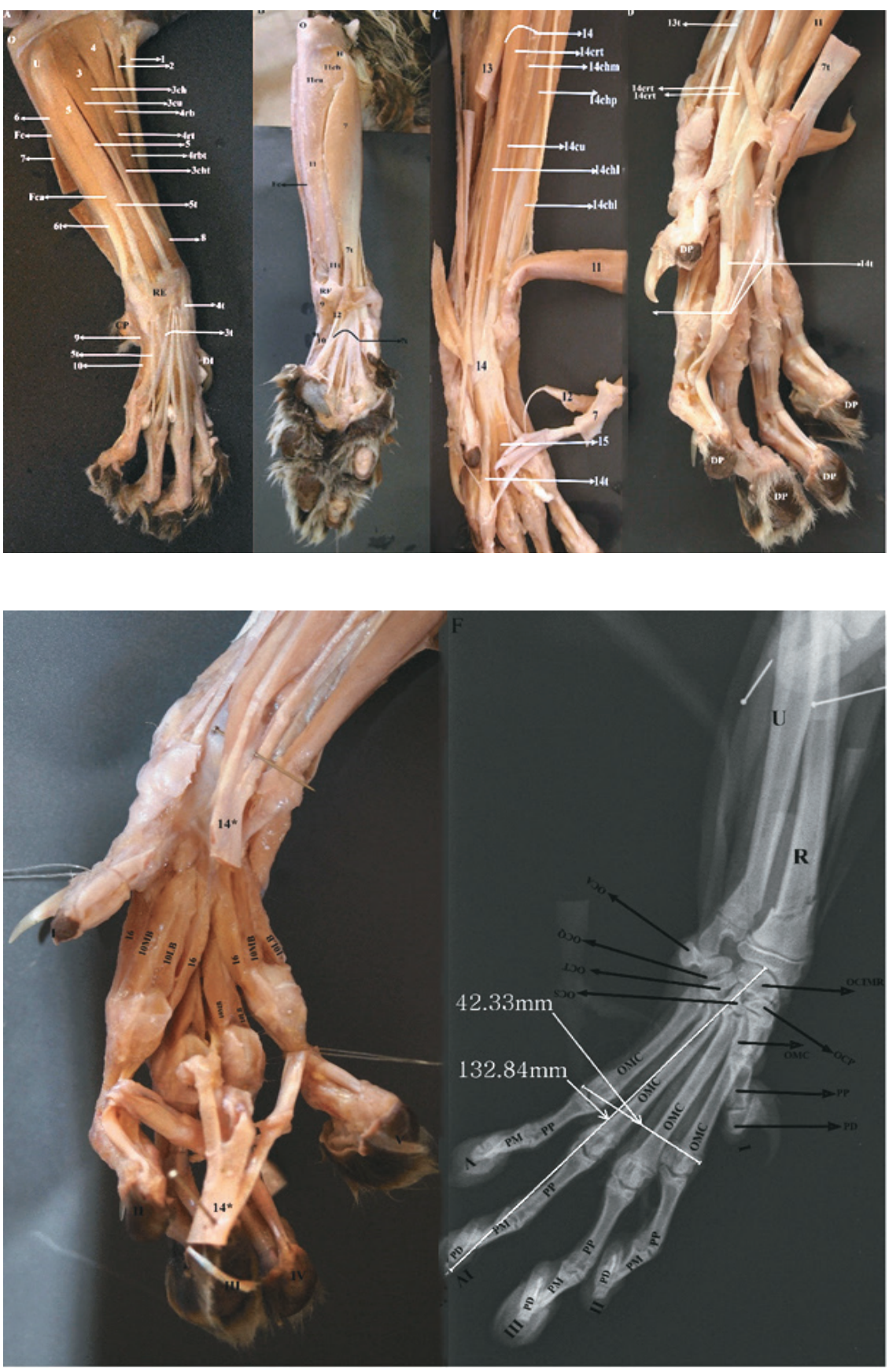

Figure 1: A-The cranial aspect of the antebrachium and manus B- The superficial caudal aspect of the antebrachium and manus $\mathrm{C}$ - The deep caudal aspect of the antebrachium and manus D- The deep palmar aspect of the manus
Figure 2: E- The deep palmar aspect of the fingers $\mathrm{F}$ - The radiography of the manus
The $\mathrm{m}$. brachioradialis located on the cranial border of the forearm and beneath the skin originated from the caudal aspect of the distal humeral shaft as broad and fan-shaped in the two cadavers (Fig. 1A/2). The muscle that got thinner at the cranial aspect of the elbow joint travelled distally on the cranial aspect of the antebrachium. After it passed over the $\mathrm{m}$. abductor digiti I longus at the level of the distal quarter of the antebrachium, the $\mathrm{m}$. brachioradialis ended on the dorsal aspect of the radial carpal bone.
The $\mathrm{m}$. extensor carpi radial longus that is fused with the $\mathrm{m}$. extensor carpi radial brevis originated from the lateral supracondylar ridge of the distal humerus in both cadavers (Fig. 1A/4rl). In the two cadavers, both muscles distally continued between the $\mathrm{m}$. brachioradialis and the $\mathrm{m}$. extensor digitorum communis on craniolateral aspect of the forearm. While the $\mathrm{m}$. extensor carpi radialis brevis (Fig. 1A/4rb) gave rise to a thin tendon at the mid-antebrachium, the $\mathrm{m}$. extensor carpi radialis longus distally extended, 
DI. The first finger

O. The olecranon

U. The ulna

I. The first finger

II. The second finger

III. The third finger

IV. The fourth finger

$\mathrm{V}$. The fifth finger

CP. The carpal pad

$\mathrm{RF}$. The retinaculum extensorum

$\mathrm{RF}$. The retinaculum flexorum

MCP. The metacarpal pad

$\mathrm{H}$. The humerus

$\mathrm{R}$. The radial bone

OCA. The accessory carpal bone

OCIM. The intermedioradial bone

OCP. The first carpal bone

OCS. The second carpal bone

OCT. The third carpal bone

OCQ. The fourth carpal bone

OMC. The metacarpal bone

PP. The proximalis phalanx bone

PM. The second phalanx bone

PD. The distal phalanx bone

DP. The digital pad

dal. The distal annular ligament

pal . The proximal annular ligament

Fc. Fascia

1. N. musculocutaneus

2. The brachioradial muscle

3. The common digital extensor muscle (CDEM)

$3 \mathrm{ch}$. The humeral head of the CDEM

$3 \mathrm{cu}$. The ulnar head of the CDEM

$3 \mathrm{cht}$. The humeral head tendon of the CDEM

3cut. The ulnar head tendon of the CDEM

then entered deep into the $\mathrm{m}$. abductor digiti I longus at the distal quarter of the antebrachium and divided into two tendons. The tendons passed under a common extensor retinaculum on the dorsal carpus. While the intertion of the thin tendon was at the dorsal aspect of the base of the second metacarpal bone, the stout tendon inserted onto the dorsomedial aspects of the base of the third metacarpal bone in the two cadavers.

The $\mathrm{m}$. extensor carpi ulnaris located at the caudolateral positon in the forearm and enclosed
4. The radial extensor of the manus (REM)

$4 \mathrm{rb}$. The radial extensor brevis of the manus (REBM)

4rbt. The tendon of the REBM

$4 \mathrm{rl}$. The radial extensor longus of the manus

5. The lateral digital extensor muscle (LDEM)

$5 t$. The tendon of the LDEM

6. The ulnar flexor of the manus (UFM) $6 \mathrm{t}$. The tendon of the UFM

7. The superficial digital flexor muscle (SDFM)

8. The adductor digiti I muscle

9. The abductor digiti V muscle (ADVM) 9t. The tendon of the ADVM

10. The flexor brevis profundus muscle (FBPM) 10MB. The medial belly of the FBPM 10LB. The lateral belly of the FBPM 10t. The tendon of the FBPM

11. The ulnar flexor of the manus (UFM) $11 \mathrm{ch}$. The humeral head of the UFM $11 \mathrm{cu}$. The ulnar head of the UFM $11 \mathrm{t}$. The tendon of the UFM

12. The flexor digital brevis manus (FDBM)

13. The radial flexor of the manus (RFM)

14. The deep digital flexor muscle (DGFM) $14 \mathrm{chm}$. The humeral medial head of the DGFM

14chp. The profound humeral head of the DGFM

$14 \mathrm{chpt}$. The profound humeral head tendon of the DGFM

$14 \mathrm{crt}$. The radial head of the DGFM

14chl. The lateral humeral head of the DGFM $14 \mathrm{cu}$. The ulnar head of the DGFM

14cut. The ulnar head of the DGFM

15. The lumbricalis muscles

16. The adductor digital muscles

fascia, which emerged from the caudal border of the $\mathrm{m}$. extensor digitorum lateralis, originated from the lateral epicondyle of the humerus in the two cadavers (Fig. 1A/6). The muscle that runs along the caudal border of the lateral digit gave rise to a tendon (Fig. 1A/6t) in the distal quarter of the antebrachium that passed through the retinaculum extensorium in the two cadavers (Fig. 1A/RE). The tendon inserted into the dorsal aspect of the basis of the fourth metacarpal bone. 
The $\mathrm{m}$. extensor digitorum lateralis situated in the lateral position in the forearm stemmed from the lateral aspect of the olecranon and from the lateral supracondylar bridge of the distal humerus in the two cadavers (Fig. 1A/5). The muscle travelled distally and then gave rise to a tendon (Fig. 1A/5t) in the mid-antebrachium that passed through the extensor retinaculum on the dorsolateral aspect of the manus. In its course, the fasciae (Fig. $1 \mathrm{~A} / \mathrm{Fc}$ ) originate from both the cranial and the caudal border of the muscle. After the course under the retinaculum, the tendon divided into three branches on the dorsal aspect of the fourth and third metacarpal bones in both cadavers (Fig. 1A/5T IV-III). The medial branch run in the distomedial direction on the dorsal aspect of the metacarpal bone and under the common digital extensor tendon to reached the dorsal aspect of the fetlock joint. The branch inserted on the dorsal aspect of the middle phalanx of the third finger in the two cadavers (Fig. 1A/5t111). The middle branch travelled in the distomedial direction to arrived at the lateral aspect of the fetlock joint in the fourth finger. Then, the branch inserted on the middle phalanx in the fourth finger (Fig. 1A/51v). The lateral branch, after origin, continued along the caudal border of the fifth metacarpal bone to reached the dorsal aspect of the fetlock joint in the fifth finger. The branch ended at the middle phalanx of the fifth finger in both cadavers.

The $\mathrm{m}$. extensor digitorum communis was composed of three bellies originated from the humerus (caput humerale; Fig. 1A/3ch), the ulna (caput ulnare; Fig. 1A/3u), and the olecranon (capita olecranon) in the two cadavers. The capita olecranon that was the weakest belly emerged from the lateral aspect of the olecranon and then passed under its origin at the lateral digital extensor muscle in both cadavers. The muscle belly fused with the caput humerale in the proximal antebrachium. The humeral head arose from the lateral supracondylar bridge and epicondylus of the humerus to reached the cranial aspect of the elbow joint in the two cadavers (Fig. 1A/3ch). The belly that was covered by the fascia originated from the $\mathrm{m}$. extensor digitorum lateralis in the proximal antebrachium and travelled distally on the cranial aspect in the proximal antebrachium. The caudal portion of the belly became a tendon in the mid-antebrachium, while the cranial portion of the belly became a tendon in the distal radius (Fig. 1A/3cht). The caput ulnare arose from the lateral aspect of the ulna and then run distally between the $\mathrm{m}$. extensor digitorum lateralis and $\mathrm{m}$. extensor carpi radialis longus in the lateral aspect in the antebrachium to turned into a tendon in the proximal antebrachium (Fig. 1A/cut). The tendons of the bellies that were covered by the fascia in the lateral aspect of the forearm, the latter extensor retinaculum in the dorsal aspect of the carpal joint, continue distally to reached the base of the third metacarpal bone in each cadaver (Fig. 1A/3hi11). The common tendon divided into four tendons that served each digit (II-V) at the base of the third metacarpal bone. Each tendon branch run distally along the dorsal aspect of the metacarpal bone to end at the extensor process of the distal phalanx associated with digits II-V (Fig. $1 \mathrm{~A} / 3 \mathrm{ch} 11-111-1 \mathrm{~V}-\mathrm{v})$. During this course, each tendon made the expansion on the dorsal aspect of both the fetlock joint and the proximal interdigital joint associated with the digits.

The $\mathrm{m}$. abductor pollicis originated from the shaft of the radius and ulna in the distal half of the antebrachium in both cadavers. It crossed obliquely in the craniodistal position in the distal quarter of the antebrachium to arrived at the extensor retinaculum (Fig. 1A/8). The muscle that covered the extensor retinaculum in the dorsal aspect of the carpal joint passed between the tendons of the $\mathrm{m}$. extensor digitorum communis and $\mathrm{m}$. extensor carpi radialis longus to become a tendon in the two cadavers (Fig. 1A/8). Its tendon inserted onto the dorsal aspect of the first carpal bone and the base of the first metacarpal bone.

The $\mathrm{m}$. flexor carpi ulnaris composed of two bellies (caput humerale (Fig. 1B/11ch) and ulnare (Fig. $1 \mathrm{~B} / 11 \mathrm{cu}$ ) located on the caudal aspect of the antebrachium. The caput ulnare that was thinner than the caput humerale arose from the caudomedial aspect of the olecranon and travelled along the caudal border of the caput humerale. The muscle got thinner and thinner and became a thin tendon situated caudally to the caput humerale in the mid-antebrachium (Fig1B/11cu). The tendon continued distally to join with the tendon of the caput humerale deep into the carpal pad in the two cadavers (Fig. 1B/11cu). The strongest caput humerale originated from the medial epicondyle of the humerus between the origin of the caput ulnare and the $\mathrm{m}$. flexor digitorum superficialis and became the strongest tendon (Fig. 1B/11cht) in the distal quarter of the antebrachium in the two cadavers. The tendon fused with the tendon of 
another head passed through the retinaculum on the lateral side of the palmar carpus and ended at the accessory carpal bone in both cadavers (Fig. 1B/11t).

The $\mathrm{m}$. flexor carpi radialis (Fig. 1B/13) situated on the caudal aspect of the antebrachium, just under the skin and fascia, arose from the medial epicondyle of the humerus. The muscle covered by fascia continued distally in the groove located cranially to the caput humerale of the $\mathrm{m}$. flexor digitorum profundus to gave rise to a tendon on the distal third of the antebrachium in the two cadavers. Then, the tendon passed through a shared retinaculum on the medial side of the palmar manus to insert on the base of the third metacarpal bone in both cadavers (Fig. 1B/13t).

The $\mathrm{m}$. flexor digitorum superficialis covered by the fascia originated from the caudal border of the $\mathrm{m}$. flexor carpi radialis and arose from the medial epicondyle of the humerus (Fig. 1B/7). The muscle located under the skin travelled distally on the caudal aspect of the forearm and became the strongest tendon in the mid-antebrachium in the two cadavers (Fig. 1B/7t). In the distal quarter of the antebrachium, this tendon gave rise to a thin branch serving the carpal pad and the superficial bellies of the $\mathrm{m}$. flexor digitorum brevis, then passed through the common retinaculum in the palmar aspect of the manus to divided into five branches serving each associated digit in the two cadavers (Fig. 1B/7t1-v). A slender branch served the first digit originated from the tendon of the $\mathrm{m}$. flexor digitorum superficialis and inserts on the base of the proximal phalanx in the first digit (Fig. 1B/11t1). Another four branches travelled under the metacarpal pad in the palmar aspect of the forepaw ended at the palmar aspect at the base of the phalanx secunda associated with the digits. Each branch was perforated by the branch of the profound digital flexor tendon at the level of the insertion.

The superficial bellies of the $\mathrm{m}$. flexor digitorum brevis originated from the tendon of the $m$. flexor digitorum superficialis in the distal quarter of the antebrachium, while the profound bellies arose from the retinaculum flexorum in the palmar aspect of the carpal joint (Fig. 1B/12). The superficial bellies with the tendon of the $\mathrm{m}$. flexor digitorum superficialis passed under the laid retinaculum flexorum and turned into a tendon deep in the metacarpal pad. The tendon laid distally under the metacarpal pad to the palmar aspect of the metacarpal bones IV-V (Fig. 1B/12).
The $\mathrm{m}$. flexor digitorum profundus arose from the distinct area as five heads in the two cadavers (Fig. 1C/14). The heads of the $\mathrm{m}$. flexor digitorum profundus laid distally on the mediocaudal aspect of the antebrachium and inserted deep into the $\mathrm{m}$. flexor digitorum superficialis and became a stout tendon (Fig. 1C/14*) (the common tendon of the heads of $\mathrm{m}$. flexor digitorum profundus) under the metacarpal pad. The belly that originated from the medial border in the proximal third of the radius and called the capita radiale (Fig. $1 \mathrm{C} / 14 \mathrm{cr}$ ) travelled distally and became a tendon (Fig. 1C/14rdt) in the distal quarter of the antebrachium. The tendon passed through the flexor retinaculum in the palmar aspect of the carpal joint to contributed to the tendon of the $\mathrm{m}$. flexor digitorum profundus under the metacarpal pad. The caput ulnare (Fig. 1C/14cu) arose from the caudal aspect of the proximal ulna, and the muscle laid distally on the caudal aspect of the interosseous membrane. The muscle's superficial portion became a tendon that contributed to the common tendon of the $\mathrm{m}$. flexor digitorum profundus at the level of the mid-antebrachium, while the muscle's profound portion directly inserted on the common tendon of both the right and left paws in the two cadavers. The caput humerale mediale (Fig. $1 \mathrm{C} / 14 \mathrm{chm}$ ) that originated from the medial epicondyle by a wide tendon (Fig. 1C/14chmt) run distally on the caudal aspect of the antebrachium, deeps into the $\mathrm{m}$. flexor digitorum superficialis, to became a tendon in the distal quarter of the antebrachium. Then, the tendon passed under the flexor retinaculum in the palmar aspect of the carpal joint to contributed to the common tendon of the $\mathrm{m}$. flexor digitorum profundus in both limbs (Fig. 1C/14chmt). The caput humerale laterale (Fig. $1 \mathrm{C} / 14 \mathrm{cml}$ ) that originated from the medial epicondyle of the humerus in the two heads turned into a tendon (Fig. 1C/14chlt) in the mid-antebrachium, deep into the $\mathrm{m}$. flexor digitorum superficialis in the two cadavers (Fig. $1 \mathrm{C} / 14 \mathrm{chlt}$ ). The caput humerale profundus (Fig. $1 \mathrm{C} / 14 \mathrm{chp}$ ) situated in the deepest originates from the medial epicondyle of the humerus and then became a tendon (Fig. 1C/14chpt) in the distal third of the antebrachium. After passed under the flexor retinaculum, the tendon ended to contribute to the common tendon of the $\mathrm{m}$. flexor digitorum profundus in both limbs (Fig. 1C/14*). The common tendon of the $\mathrm{m}$. flexor digitorum profundus laid deep in the metacarpal pad in the carpal tunnel and firstly gave rise to slender a tendon in 
the first finger in the mid-metacarpal bone (Fig. $1 \mathrm{C} / 14 \mathrm{t} 1)$. The common tendon broke off into four branches (II, III, IV, V) (Fig. 1C/1411-v) to each finger deep in the metacarpal pad in the two cadavers. Each tendon branch laid distally in the palmar aspect of the metacarpal bone associated with the finger to initially passed through the proximal annular ligament in the palmar aspect of the fetlock (Fig. 1C/pal); shortly after, it passed through the superficial digital flexor tendon, and finally, the distal annular ligament (Fig. 1C/dal) in the mid-proximal phalanx, ending at the muscular tubercle of the distal phalanx (Fig. 1C/14t1-v).

The $\mathrm{m}$. abductor digiti $\mathrm{V}$ that arose from the palmar aspect of the accessory carpal bone and had a triangle shape turned into a tendon in the mid-first metacarpal bone in the two cadavers (Fig. 1B/9). Then, the tendon laid distally on the lateral aspect of the first finger to inserted onto the palmar aspect of the proximal phalanx of the first finger (Fig. 1B/9t).

The $\mathrm{mm}$. lumbricales situated on the palmar aspect of the profound digital flexor tendon and under the superficial digital flexor tendon arose from the profound digital flexor tendon as four bellies at the metacarpal pad (Fig. 1C/15). Then, the bellies descended distally deep into the metacarpal pad to became a tendon in the palmar aspect of the fetlock joint. Each tendon ended at the palmar aspect of the bases of metacarpal bones II-IV.

The $\mathrm{mm}$. flexores digitorum profundi breves composed of five distinct muscles originated from the distal row of carpal bones and laid distally on the palmar aspect of the metacarpal bone in each finger to ended at the palmar aspect of the base of the proximal phalanx (Fig. 2E/10LB-MB). Each muscle consisted of lateral and medial bellies. The weakest of the $\mathrm{mm}$. flexores digitorum profundi breves was the $\mathrm{m}$. flexor digiti I brevis (Fig. 2E/10LB-MB).

The $\mathrm{mm}$. adductores originated from the distal row of carpal bones and run distally firstly to the palmar aspect and finally to the interdigital aspect of each metacarpal bone associated with the finger to inserted onto the interdigital aspect of the proximal phalanx in each finger (Fig. 2E/16).

\section{Discussion}

The muscles and their tendons acting on the digital and carpal joints in the forelimb's paw, as described by Julik et al. (8), are sorted as located in the cranial and caudal compartments of the antebrachium and, the superficial, central and hypothenar compartments of the manus. As has been described in previous literature $(8,9$, $10,11,12)$, it was observed that extensor group muscles are located in the cranial aspect of the antebrachium. In this study, the origin of the radial extensor muscles of the manus is similar to that in carnivores, as depicted in the literature $(8,9,10,11)$, but the insertion tendon of the long portion of the muscle ending at the second metacarpal bone is different from what was described in the literature on carnivores $(8,9,10$, $11,12)$. It was previously described that the origin of the $\mathrm{m}$. extensor digitorum lateralis was the lateral supracondylar bridge of the humerus and the superficial aspect of the supinator muscle in the ocelot (8). However, in the present study, the origin of the muscle has been observed to be the lateral supracondylar bridge of the humerus and the lateral aspect of the olecranon. The finding that the fascia originate from both the cranial and caudal border of the muscle was firstly obtained in the present study. As was described in the ocelot (8), it has been seen that the muscles turn into a stout tendon in the mid-antebrachium and pass under the extensor retinaculum in the dorsal aspect of the carpal joints. However, it has been revealed that the tendon of the muscle divides into three branches, and each branch inserts onto the dorsal aspect of the second phalanx of the third, fourth, and fifth fingers in the Anatolian bobcat. Although it has been reported that the m. extensor digitorum communis arises from a different area of the humerus in carnivores $(8,9,10,11,12)$, in the present research, it was found that the muscle originates from the ulna, olecranon, and the lateral supracondylar bridge as three heads. In addition, in this study, it was observed that the ulnar head turns into a tendon in the proximal antebrachium. While becoming a tendon of the cranial portion of the humeral head is the distal radius, those of the caudal portion of the humeral head is in the mid-antebrachium in the Anatolian bobcat. As was described in the ocelot (8), the tendon of the muscle passes under the common extensor retinaculum and divides into four branches for each finger (II-V) in the research. It has been seen that each branch enlarges in the dorsal aspect of fetlock and the proximal interdigital joint and ends at the extensor process of the distal phalanx of the associated finger. 
In this study, as described in the literature $(8$, $9,10,11,12)$, it has been seen that the flexor muscle group of the forearm situated at the caudal aspect of the antebrachium and their tendons act on the forepaw in the Anatolian bobcat. In this study, it was found that the $\mathrm{m}$. flexor carpi ulnaris arises from both the olecranon and the medial epicondyle of the humerus as two heads, as depicted in the research $(8,9,10,11)$. In the Anatolian bobcat, it has been seen that the region in which the caput ulnare turns into a tendon is in the mid-antebrachium, while for the caput humerale, it is in the distal quarter of the antebrachium. In the study, the findings of the muscle insertion are similar to those described in the literature on carnivores $(8,9,10,11)$. The origin and insertion of the $\mathrm{m}$. flexor carpi radialis in the Anatolian bobcat are similar to what has been reported in the literature. However, in this study, it was observed that the muscle turns into tendon in the distal third of the antebrachium. The findings about the origin and location of the $\mathrm{m}$. flexor digitorum superficialis obtained in this study are similar to the data given in the literature about carnivores $(8,9,10,11)$. However, Julik et al. (8) called the muscle the palmaris longus in the ocelot. As described by many authors $(8,9$, $10,11)$, it has been found that the tendon of the muscle divides into five branches in the palmar aspect of the carpal joints in the Anatolian bobcat. However, in this study, it was observed that the tendon of the muscle gives rise to the superficial portion of the $\mathrm{m}$. flexor digitorum brevis and a thin tendon serving the carpal pad. In addition, each tendon associated with the fingers is perforated by a deep digital flexor tendon at the level of the palmar aspect of the base of the phalanx media in the Anatolian bobcat. As previously depicted by Julik et al. (8), the $\mathrm{m}$. flexor digitorum profundus in five separate heads arises from the distal humerus, the proximal part of the ulna, and the radius in the Anatolian bobcat. In this study, as in the investigation by Julik et al. (8) in the ocelot, the heads have been named as the radial, ulnar and deep, medial, and lateral humeral heads in the Anatolian bobcat. In this study, it was observed that a stout tendon forms to unite all heads in the palmar aspect of the antebrachium. The tendon gives rise not only to the tendon branch for the muscular tubercle of the phalanx distalis, but also to the $\mathrm{mm}$. lumbricalis in each finger, except the first finger, in the Anatolian bobcat. Furthermore, in this study, it was found that each tendon associated with each finger passes through both the superficial digital flexor tendon and proximal and distal annular ligament related to each finger. The findings about the $\mathrm{mm}$. lumbricalis and its tendons obtained from this study are similar to the data expressed by Julik et al. (8) in ocelots.

The evidence related to the origin and insertion of the central muscles of the manus observed in this study is similar to the outcomes described by Julik et al. (8) for the ocelot. However, in the present study, it was seen that each $\mathrm{mm}$. flexores digitorum profundi breves consists of lateral and medial bellies.

In conclusion, our investigation showed that the fasciae, muscles, and tendons of the forepaw are well-developed in the Anatolian bobcat. In particular, the $\mathrm{m}$. flexor digitorum pprofundus and its stout tendon both work as flexor functions of fingers and give rise the $\mathrm{mm}$. lumbricales. In addition, the flexor muscles in the palmar aspect of the antebrachium, its tendons, and the muscles of the central manus play a role not only in the organs of the locomotor system, but also in subduing struggling prey for the Anatolian bobcat. The muscle and tendon structures of the forepaw may be advantageous for the hunting and survival of the Anatolian bobcat.

\section{Acknowledgment}

This research has not received any special grants. Permission was obtained from the Republic Turkey Ministry of the Agriculture and Forestry Affairs for Study.

Authors declare that there is no conflict of interests regarding the publication of this article.

\section{References}

1. Özgel O, Aykut M. Macroanatomical investigation on ossa membri pelvini of Anatolian bobcat Lynx. Pakistan J Zool 2015; 47: 1492-4.

2. Arı HH, Kuru N, Uslu S, Özdemir Ö. Morphological and histological study on the foot pads of the Anatolian bobcats (Lynx lynx). Anat Rec 2018; 301: 932-8.

3. Iwanuik AN, Pellis SM, Whishaw IQ. The relationship between forelims morphology and behaviour in North American carnivores (Carnivora). Can J Zool 1999; 77: 1064-74. 
4. Andersson K. Elbow-joint morphology as a guide to forearms function and foraging behaviour in mammalian carnivores. Zool J Linn Soc Lond 2004; 142: 91-104.

5. Meachen-Samuels J, Van Valkerburgh B. Forelimb indicator of the prey-size prefence in $\mathrm{Fe}$ lidae. J Morphol 2009; 270: 729-44.

6. Oliveira TGD. Leopardus wiedii. Mammal Species 1998; 579: 1-6.

7. Tanaka M. Fins into limbs: Autopod acquisition and anterior elements reduction by modifying gene networks involving 5'Hox, Gli3, and Shh. Dev Biol 2016; 413(1): 1-17.

8. Julik E, Zack S, Adrian B, et al. Functional anatomy of the forelimbs muscles of the ocelot (Leopardus pardalis). J Mamm Evol 2012; 19: 227-304.

9. Getty R. Sisson and Grossman's the anatomy of the domestic animals. Philadelphia; London; Toronto : WB Saunders Company, 1975.

10. König HE, Liebich HG. Veterinary anatomy of domestic mammals. $6^{\text {th }}$ ed. Stuttgart : Shattauer, 2015.
11. Nickel R, Shummer A, Seiferle E, Frewein J, Wilkens H, Wille KH. The anatomy of the domestic animals. Vol. 1: The locomotor system of the domestic animals. Berlin; Hamburg : Paul Parey, 1986.

12. Dyce KM, Sack WO, Wensing CJG. Textbook of veterinary anatomy. Philadelphia : Saunders, 1996.

13. Hubbard C, Naples V, Ross E, Carlon B. Comparative analysis of paw pad structure in the Clouded leopard (Neofelis nebulosa) and domestic cat (Felis catus). Anat Rec 2009; 292: 1213-28.

14. Cumhuriyet University was delivered dead Lynx in Sivas in order to make the post-mortem examination. 2016. www.sivas.ormansu.gov.tr/ sivas/Anasayfa/resimliHaber.

15. World Association of Veterinary Anatomists. International Committee on Veterinary Gross Anatomical Nomenclature. Nomina anatomica veterinaria. $5^{\text {th }}$ ed. Hannover; Ghent; Sapporo: The Editorial Committee Hannover, 2012: 13.

\title{
MAKROSKOPSKA ŠTUDIJA KIT IN MIŠIC SPREDNJE ŠAPE PRI RISU (Lynx lynx)
}

\author{
H. H. Ari, I. Yurdakul, G. Aksoy
}

Povzetek: V raziskavi smo proučili kite in mišice sprednje šape pri dveh risih (Lynx lynx). Material za raziskavo je darovalo Ministrstvo za gozdarstvo in vode Turčije. Na dveh kadavrih je bila izvedena radiografija in sekcija. Radiografija je pokazala, da je prvi prst sprednje šape rudimentaren. Mišice in kite sprednje šape se pri risu nahajajo v kranialnem in kavdalnem področju podlahti, centralnega dela dlani in na področju mišic, ki premikajo 5. prst. Mišice iztegovalke se nahajajo na sprednjem delu podlahti, medtem ko so mišice upogibalke nameščene na kavdalnem področju podlahti. Ena izmed mišic iztegovalk $m$. extensorcarpi radialis ima dolge in kratke odseke; iz mišice m. extensor digitorum lateralis et communis izhajajo kite za prste; fascija, ki pokriva mišice pa se začne na lateralnem in medialnem področju mišice m. extensor digitorum lateralis. Mišica m. flexor digitorum superficialis et profundus leži na kavdalnem področju podlahti; iz površinskih tetiv digitalnega fleksorja pa izhaja trebuh mišice $m$. flexor digitorum brevis; $m$. flexor digitorum profundus tvori močno tetivo, iz katere $\mathrm{mm}$. lumbricales izvirajo na palmarnem področju karpalnih sklepov. Tetiva mišice perforira tetivo mišice $m$. flexor digitorum superficialis. Mišice $m m$. flexores digitorum profundiv osrednji skupini mišic področja dlani so sestavljene iz lateralnih in medialnih delov in se nahajajo na palmarnem področju vsake proksimalne prstnice in so povezane s prsti. Druge mišice v skupini $\mathrm{mm}$. adductores digitorum, se končajo na koncih istih prstov.

Ključne besede: ris (Lynxlynx); sprednja šapa; mišice; kite; anatomija 